\title{
Vulnerability of Rice Production in Mekong River Delta under Impacts from Floods, Salinity and Climate Change
}

\author{
Nguyen Ngoc Thuy ${ }^{\#}$, Hoang Ha Anh ${ }^{*}$ \\ \# Office of International Relationship, Nong Lam University Ho Chi Minh city, Vietnam \\ E-mail:nnthuy@hcmuaf.edu.vn \\ *Faculty of Economics, Nong Lam University Ho Chi Minh city, Vietnam \\ E-mail: hoanghaanh@hcmuaf.edu.vn
}

\begin{abstract}
This study sought to estimate the floods and salinity impact index and climate change vulnerability index for the rice farming provinces in Mekong River Delta. In both indexes, Tra Vinh province and the communes within it have the highest index value, followed by other coastal provinces. The estimation showed that the rice production in these areas are being threatened and will be worsen if there is no appropriate plan to cope with the changes in climate condition and extreme events. The results for the simulation model of paddy yield under different scenarios showed decreases in the paddy yield in Mekong River Delta. Specifically, the yield of Spring paddy decreases $6 \%$, Autumn paddy decreases $2 \%$, Winter paddy decreases $4 \%$ and Autumn-winter paddy decreases $4 \%$ in 2050 . From these results, the climate change adaptation and mitigation policies in this delta is suggested to be focused reducing the exposure to sea level rise; upgrading the irrigation system for paddy planting since the coastal provinces have high rate of rain-fed paddy, vulnerability can also be reduced by enhancing the adaptive capacity of provinces through subsidizing and providing farmers with new paddy varieties which are more tolerant to salinity.
\end{abstract}

Keywords - rice production, vulnerability, climate change, floods, Mekong River Delta

\section{INTRODUCTION}

Vietnam is a developing country that has agriculture as a traditional economic sector. Currently, Vietnam is the second biggest rice exporting country in the world. In 2012, the country exported about 7.65-7.7 million tons of rice (Vietnam Food Association). The Mekong River Delta, which is the largest rice production in Vietnam, is located in southwestern Vietnam. There are 2.6 million hectares in the Mekong River Delta which are used for agriculture production, less than $30 \%$ of the country's total but it contributes more than $50 \%$ of Vietnam's total output. In 2011 , the rice output was $23,186,000$ tons [1].

Agriculture in general or rice production in specific is a climate-sensitive sector and unfortunately Vietnam is a country that can easily be affected by climate variability. There are many factors that can influence agriculture such as changes in rainfall, temperature conditions or changes in soils.

Because of its geographical charactieristics, the Mekong River Delta has annually been suffering 4 to 6 months of floods and 5 months of salf water intrusion which cause losses to rice production area, rice yield and other damages to farmers's livelihood in the region. The numbers of people living in flooded areas are up to 8.5 million people of which 2.5 million people suffer 3 meters deep flood water and 3 million people suffer 1.5 meters deep flood water [2].

Another concern from extreme event is the salinity problem because the tide level of the Mekong river is lower than the high tide at sea, so the flow of the Mekong inverts with the tides, carrying water inland. This also means that salinity and erosion problems would occur. During dry season, sea water moves into 70 kilometers from the coast [3]. This issue can change the spatial structure or configuration of the landscape since the salinity can affect both the characteristics of water and soil elements of the pattern, causes corruption in the nutrient flow and then creates negative impacts on rice farming in the region since rice has low resistance to salinity.

Beside these factors, climate change which is a global concern is becoming a threat to rice production. Compared to developed countries, developing countries seem to have more difficulties coping to climate change in terms of adapting capacity. Moreover, the rural people in developing countries would be the ones who are more vulnerable to impacts of climate change [4] because the sectors that suffer climate change are agriculture, water availability, food 
security and aquaculture which are usually the sources of livelihood of rural people. In the high emission scenario for temperature and rainfall in Vietnam, at the end of the 21st century, the annual average temperature may increase from $2.5^{\circ} \mathrm{C}$ to $3.7^{\circ} \mathrm{C}$ while the annual rainfall amount may increase from $2 \%$ to $10 \%$ [5]. The changes in temperature and rainfall can cause impact on paddy production in terms of changes in evapotranspiration, growth stages or biomass production [6].

Most of the studies about climate change in the region focused on the impacts, vulnerability and adaptation of the delta [7, 8]. According to Chaudhry and Ruysschaert [9], the Mekong River Delta of Vietnam has to face with the potential of sea level rise and increasing intensive floods as well as drought. The occurrence of floods in 2000 and 2001 killed 481 and 393 people, respectively, along with many damages in livelihoods and economy while in the dry season, salt intrusion becomes harmful. Among the possible effects of global warming, sea level rise is the one that may create the most damages on the delta since it may enhance the floods in term of magnitude, duration and intensity [10]. The cumulative effect of storm surges and sea level rise is projected to increase the 2000 year flood to a depth of 2.5 meters over a 4300 kilometer square area [11]. However, Västilä, Kummu, Sangmanee and Chinvanno [10] stated that although in the worst case, sea level rise and floods may cause severe damages to crops.

Changes in paddy production due to extreme events can be a critical problem since it is the most important crop in agricultural production and food security in Vietnam [7, 12]. Using climate change scenario for sea level rise from MONRE [5], the loss of rice production in 2050 are 0.89 million tons in rainy season and 1.77 million tons in dry season; the affected rice areas are 193 thousand hectares in rainy season and 294 thousand hectares in dry season [13].

Because the sustainability of rice production in the Mekong River Delta can be damaged, understanding potential impacts from climate change, floods and salinity is necessary and may provide useful information for the government and local authorities in designing and planning mitigation and adaptation plans. This study sought to assess the vulnerability of rice production to flooding, salinity and climate change in Mekong River Delta of Vietnam. The specific objectives are: (1) to evaluate the potential impact index of flooding and salinity of Mekong River Delta; (2) to assess the climate change vulnerability of Mekong River Delta; and (3) to project the changes in rice yield of Mekong River Delta under different climate scenarios.

\section{METHODOLOGY}

The study will conduct the assessment in different level based on the characteristics of the extreme events. In order to evaluate the impact index of floods and salnity, data from communal level will be used to reflect specific impact levels that floods and salinity have being created on the communities in the Mekong River Delta annually. Then, because climate change is commonly used to refer as an overall threat to the region, a vulnerability index at provincal level will be estimated to serve as indicators for the state of provinces within the delta.

The first and second objective of the study will be made by building floods and salinity potential impact index and climate change vulnerability index. Both of these indexes contain different set of indicators.

\section{A. Evaluating floods and salinity potential impact index}

Potential impact index (PII) includes exposure and sensitivity to analyze the degree that floods and salinity affect livelihood of people within study areas. The indicators of PII are presented in Table 1 . The PII will be determined using the formula:

$$
\mathrm{SVI}=\Sigma\left(\mathrm{W}_{\mathrm{i}} * * \mathrm{~S}_{\mathrm{i}}\right)
$$

Where

PII = potential impact index,

$\mathrm{Wi}=$ relative weighs of indicators contributing to the vulnerability, (i=1-n),

si $=$ the score (normalised value) of sub-indicators.

Based on the expected relationship in Table 1, the normalized value of sub-indicators will use one of the following formula:

$$
\begin{aligned}
& S i=\frac{\text { (Actualwhe }- \text { min walwe) }}{\text { (max wahe }- \text { min wha }}(+ \text { relationship) } \\
& \mathbf{S i}=\frac{\text { (max wahe-Aotwal wahe })}{\text { (max wahe-min wahe) }}(- \text { relationship })
\end{aligned}
$$

PII are determined firstly on commune level based on survey data then scaling up for district level.

\section{B. Assessing the climate change vulnerability}

The quantitative assessment of vulnerability was conducted by building a vulnerability index based on several indicators that represent the vulnerability of the region [14]. From the definition of vulnerability of IPCC [15] as a function of exposure, sensitivity and adaptive capacity, the indicators were also classified into these three determinants of vulnerability. The selected indicators of the study are presented in Table 2.

Predicted changes in rainfall, temperature and sea level from the selected base year are the indicators for the exposure to the system [14]. Because exposure is related to the climate stress upon the system in a long term, the study applied the predicted values from the medium emission scenario in 2050 projected by MONRE [5]. The larger the value of the changes, the more pressure placed on the system so that the vulnerability is also larger. Therefore, they have positive relationships with vulnerability. The sea level rise in the study was assumed to be purely facilitated by climate change since there is another hypothesis which states that the over extraction of ground water in the region can lead to the sink of the ground surface.

After being normalized, a Principal Components Analysis (PCA) was conducted to obtain the weights for the indicators since different indicators would have different effects on the vulnerability. PCA is widely applied in scientific research, especially in vulnerability assessment of various fields [1621]. 
After identifying the weights, the vulnerability index was constructed by applying the formula [22]:

$$
v_{i}=\sum_{i=1}^{k}\left[b_{i}\left(a_{i j}-x_{i}\right)\right] / s_{i}
$$

Where $\mathrm{v}$ is the vulnerability index, $\mathrm{b}$ is the weight, $\mathrm{a}$ is the indicator value, $\mathrm{x}$ is the mean indicator value, $\mathrm{s}$ is the standard deviation of the indicators, $i$ is indicator $i$ and $j$ is province $j$.

\section{Projecting changes in rice yield under different climate scenarios}

The study applied Aqua Crop Model to assess the rice yield reduction under different years in the different scenarios for temperature and rainfall. Aqua Crop is a model developed by FAO to simulate crop yield's responses to water. It is applicable for wide range of users including yield prediction under climate change scenarios. The model contains several components: soil; water balance; crop's characteristics, development, growth and yield; atmosphere which includes thermal regime, rainfall, evaporative demand and $\mathrm{CO} 2$ concentration; and irrigation and fertilization practices.

The rice productivities were estimated for each of rice seasons in Mekong River Delta. The impact of climate change was included in the model by changing the rainfall and temperature. The baseline scenario was the rice productivity under observed temperature and rainfall. The predicted temperature and rainfall of 2030 and 2050 in different climate change scenarios for Vietnam were then integrated in the model to analyze the change in productivity. The $\mathrm{CO} 2$ concentrations under low, medium and high emission scenarios were also incorporated. Due to the limitation of the study, other data input except temperature, rainfall and $\mathrm{CO} 2$ concentration were not changed over time.

TABLE I

VARIABLES OF POTENTIAL IMPACT INDEX (PII)

\begin{tabular}{|c|c|c|c|c|c|}
\hline Index & Determinants & No & Unit & Indicators & $\begin{array}{l}\text { Corre } \\
\text { lation }\end{array}$ \\
\hline \multirow{8}{*}{ PII } & \multirow{4}{*}{ Exposure } & $\mathrm{X} 1$ & Number & $\begin{array}{l}\text { No. of people affected } \\
\text { by flooding }\end{array}$ & + \\
\hline & & $\mathrm{X} 2$ & Number & $\begin{array}{l}\text { No. of people affected } \\
\text { changes in area affected } \\
\text { by salinity changes }\end{array}$ & + \\
\hline & & $\mathrm{X} 3$ & Number & $\begin{array}{l}\text { No. of people affected } \\
\text { by changes in livelihood } \\
\text { related to agricultural } \\
\text { activity }\end{array}$ & + \\
\hline & & $\mathrm{X} 4$ & Number & $\begin{array}{l}\text { No. of people affected } \\
\text { due by changes in } \\
\text { fishery activity }\end{array}$ & + \\
\hline & \multirow{4}{*}{ Sensitivity } & $\mathrm{X} 5$ & $\%$ & $\begin{array}{l}\% \text { of people engaged in } \\
\text { farming }\end{array}$ & + \\
\hline & & X6 & $\%$ & $\begin{array}{l}\% \text { of people engaged in } \\
\text { fishing }\end{array}$ & + \\
\hline & & $\mathrm{X} 7$ & $\%$ & $\begin{array}{l}\% \text { of people engaged in } \\
\text { aquaculture }\end{array}$ & + \\
\hline & & $\mathrm{X} 8$ & Number & $\begin{array}{l}\text { Number of households } \\
\text { that have main income } \\
\text { source from agriculture, } \\
\text { aquaculture and forestry }\end{array}$ & + \\
\hline
\end{tabular}

\begin{tabular}{|c|c|c|c|l|c|}
\hline & X9 & VND & $\begin{array}{l}\text { average Net income/hh } \\
\text { from rice production }\end{array}$ & - \\
\cline { 3 - 6 } & X10 & VND & $\begin{array}{l}\text { average Net income/hh } \\
\text { from fishery }\end{array}$ & - \\
\cline { 2 - 5 } & X11 & VND & $\begin{array}{l}\text { average Net income/hh } \\
\text { from aquaculture }\end{array}$ & - \\
\cline { 2 - 5 } & X12 & $\%$ & $\begin{array}{l}\text { \% of HHs have } \\
\text { Alternative livelihood } \\
\text { options besides } \\
\text { agricutulre, aquaculture } \\
\text { and fishery }\end{array}$ & + \\
\hline
\end{tabular}

TABLE III

INDICATORS TO ASSESS THE VULNERABILITY OF RICE FARMING PROVINCES

\begin{tabular}{|c|c|c|c|}
\hline Determinants & Indicators & Description & $\begin{array}{l}\text { Corre } \\
\text { lation }\end{array}$ \\
\hline \multirow{8}{*}{ Exposure } & Change in rainfall & \multirow{3}{*}{$\begin{array}{l}\text { Predicted changes in } \\
\text { climate variables from } \\
\text { the selected base year } \\
(1980)\end{array}$} & + \\
\hline & $\begin{array}{l}\text { Change in } \\
\text { temperature }\end{array}$ & & + \\
\hline & Change in sea level & & + \\
\hline & $\begin{array}{l}\text { High rainfall } \\
\text { extreme }\end{array}$ & \multirow{4}{*}{$\begin{array}{l}\text { Amount of differences } \\
\text { of min and max } \\
\text { rainfall and } \\
\text { temperature to the } \\
\text { mean value }\end{array}$} & + \\
\hline & $\begin{array}{l}\text { Low rainfall } \\
\text { extreme }\end{array}$ & & + \\
\hline & $\begin{array}{l}\text { High temperature } \\
\text { extreme }\end{array}$ & & + \\
\hline & $\begin{array}{l}\text { Low temperature } \\
\text { extreme }\end{array}$ & & + \\
\hline & $\begin{array}{l}\text { Topographic } \\
\text { elevation }\end{array}$ & $\begin{array}{l}\text { Average topographic } \\
\text { elevation of the } \\
\text { province }\end{array}$ & - \\
\hline \multirow{3}{*}{ Sensitivity } & Paddy land & $\begin{array}{l}\text { Percentage of paddy } \\
\text { land in total area }\end{array}$ & + \\
\hline & $\begin{array}{l}\text { Rural population } \\
\text { density }\end{array}$ & $\begin{array}{l}\text { Percentage of rural } \\
\text { population per } \mathrm{km}^{2}\end{array}$ & + \\
\hline & $\begin{array}{l}\text { Rate of rain-fed } \\
\text { paddy }\end{array}$ & $\begin{array}{l}\text { Ratio of rain-fed } \\
\text { paddy area over } \\
\text { irrigated paddy area }\end{array}$ & + \\
\hline \multirow{6}{*}{$\begin{array}{l}\text { Adaptive } \\
\text { capacity }\end{array}$} & Farm organization & $\begin{array}{l}\text { Number of } \\
\text { agricultural } \\
\text { organization in the } \\
\text { province }\end{array}$ & - \\
\hline & Literacy rate & $\begin{array}{l}\text { Proportion of people } \\
\text { who can read and } \\
\text { write }\end{array}$ & - \\
\hline & Rice output & $\begin{array}{l}\text { Output from rice } \\
\text { production }\end{array}$ & - \\
\hline & $\begin{array}{l}\text { Share of rice } \\
\text { income }\end{array}$ & $\begin{array}{l}\text { Percentage of rice } \\
\text { production in the } \\
\text { region's GDP }\end{array}$ & + \\
\hline & $\begin{array}{l}\text { Number of } \\
\text { agricultural } \\
\text { employees }\end{array}$ & $\begin{array}{l}\text { Number of employees } \\
\text { who are engaged in } \\
\text { agriculture }\end{array}$ & + \\
\hline & $\begin{array}{l}\text { Percentage of } \\
\text { poverty }\end{array}$ & $\begin{array}{l}\text { Percentage of people } \\
\text { below poverty rate }\end{array}$ & + \\
\hline
\end{tabular}

Source: [14, 23-27]

The selected study sites included 12 provinces and one city in Mekong River Delta. The data used in the study were secondary data collected from various government agencies.

Due to the limitations in budget, time and human resources, the data for sea level rise in the study was assumed to be purely facilitated by climate change and other possible factors, such as regional tectonics, over-extraction of groundwater and other similar processes that lead to the sinking of the ground surface were not considered.

In the simulation model for paddy yield, disease factors, impacts of salinity and sea level rise were not taken into 
account. Besides, other data input except temperature, rainfall and $\mathrm{CO}_{2}$ concentration would not change over time.

Although there are many varieties of paddy which are being used in different seasons and provinces, the study assumed that the characteristics of the varieties are not different and only estimated the yield of one rice variety for each delta. The study only estimated the yield of irrigated paddy.

\section{Data Collection}

The selected areas from the Mekong River Delta included 12 provinces and one central level city. Data related to climate variables of the Mekong River Delta were collected from the Mekong River Commission, Department of Natural Resources and Environment and meteorological stations across the provinces. Data on the characteristics of soil and crop were collected from Cuu Long Delta Rice Research Institute.

Soil and meteorological data, when not available or not sufficient, were gathered from worldwide databases of the Harmonized World Soil Database assembled by FAO and the Global Summary of the Day (GSOD) database archived by the National Climatic Data Center (NCDC).

Data regarding social-demographic characteristics of the region were collected through the Departments of Labor and Social Affair and Department of Health, while data on agriculture and rice production were gathered from the Department of Agriculture and Rural Development.

In order to collect primary data for evaluate impact index at communal level, a survey of 1260 households was conducted to collect information regarding livelihood options and prone state to floods and salinity.

\section{RESULTS AND FINDINGS}

Except for the three communes that are Thoi An (Can Tho province), Trung Binh (Soc Trang) and Tan Thanh (Tien Giang), most of the communes in Vietnam Mekong Delta are located in floodplain areas. Due to its mostly flat terrain, majority of the region's land can be used for agriculture and most of the agriculture land is used for rice cultivation. Kien Giang province, An Giang province and Dong Thap province are the best three producers within the region.

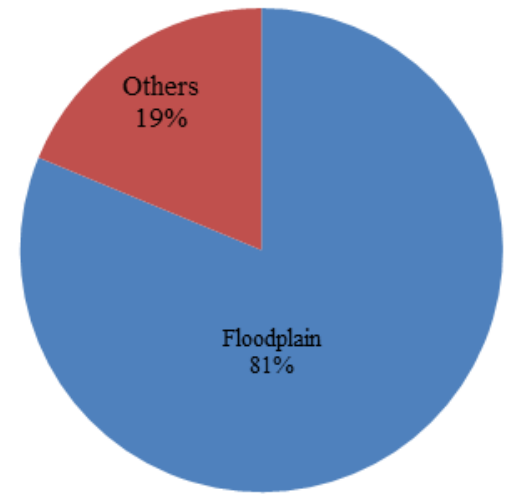

Fig. 1 Percentage of communes living in floodplain
The Mekong River Delta is very sensitive to flood and salinity because it is a low-lying coastal region. According to the result of the PRA, floods occur from the end of June until October. Recent big floods occurred in 1996, 2000 and 2011 had caused great losses on rice production, aquaculture, infrastructure and livelihood of the communities.

Among surveyed communes, Ham Tan commune (Tra Vinh) has $100 \%$ of $\mathrm{HH}$ that experienced floods in the last 3 years. In general, $48 \%$ of $\mathrm{HH}$ in provinces were affected by floods which indicate that a large portion of Vietnam Mekong delta would be vulnerable when flood pattern changes due to hydropower plants. However, the investment of dike systems can help reducing flood impacts since results of PRA in Mekong River Delta show that completed dike systems can enable farmers to increase up to 3 seasons per year even in previous floodplain areas.

Regarding to salinity, the most exposed communes are located at coastal area while below $20 \%$ of inland $\mathrm{HH}$ responded to have experienced salinity in the last 3 years. Salinity usually occurs from January to May; in 2011, coastal provinces were affected by salinity incursion combining with high tides which heavily damage paddy yield. Although increases in salinity may damage rice production, it can create favorite environment for shrimp farming which needs brackish water.

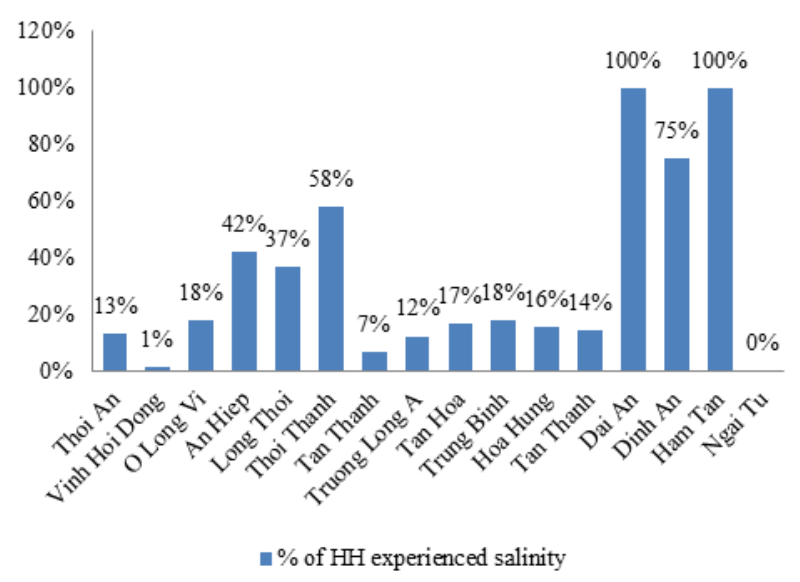

Fig. 2 Percentage of $\mathrm{HH}$ experienced salinity in Vietnam

In Mekong River Delta of Vietnam, agriculture and aquaculture are main income sources which are shown by number of households that have main income from these sectors. Rice production schedule in Mekong River Delta is different among provinces depends on hydrological regimes and irrigation systems. In places that have completed dike systems, farmers can plant 3 or 4 seasons per year even in flood prone or coastal area. In opposite, there are usually only 2 rice seasons per year in places that do not have completed dike systems. Aquaculture in Mekong River Delta is also diverse. Catfish, snakehead, prawn and shrimp are popular production. 


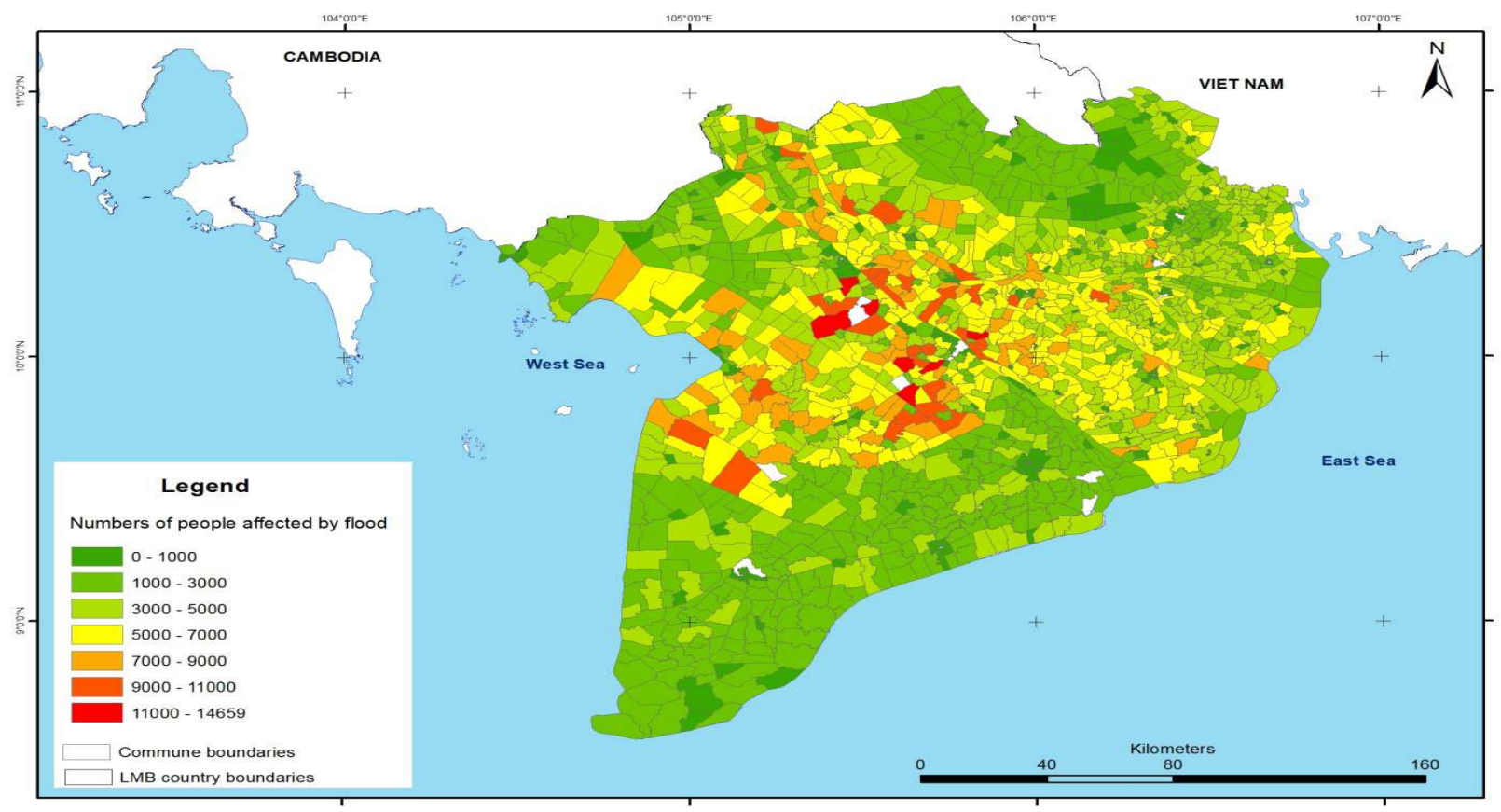

Fig. 3 Population affected by floods in Vietnam

\section{A. Potential impact index}

The result of PII for 1575 communes, within 130 districts and 13 provinces is shown as Figure 5. Among 13 provinces in Mekong River Delta, there are 9 provinces that have moderate PII. Tra Vinh has the PII since its population is affected by both floods and salinity more heavily than other provinces. Inland provinces tend to have lower PII because they are not affected by salinity as much as coastal provinces.
The potential impacts from floods and salinity on provinces might have mitigated by dike systems. After the big floods in 1996, 2000, 2011 and the salt incursion in 2011, many irrigation constructions were invested to prevent floods from upstream and salinity from coastal zones. This investment has reduced the damage, risks as well as enabled farmers to produce 3 rice seasons per year.

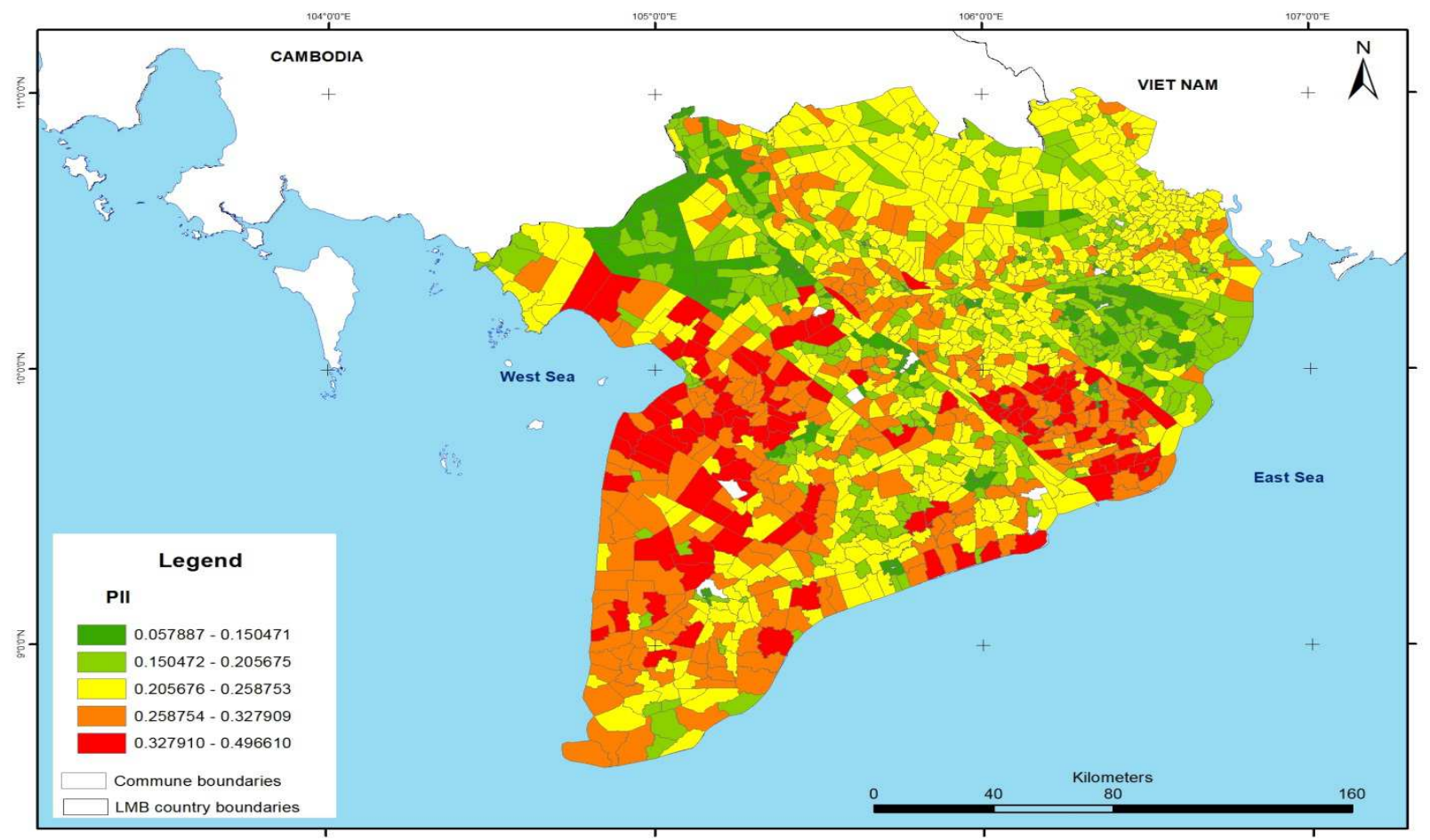

Fig. 4 PII of Vietnam provinces 


\section{B. Climate change Vulnerability index}

The research applied PCA to identify weights for each indicators. According to Kaiser Criterion, the first six components were significant with Eigenvalues greater than 1 . These six components explained $87.9 \%$ of the variations in the data set. The first principal component explained most of the variations $(32.5 \%)$, the second principal component explained $17.2 \%$, the third principal component explained $14.4 \%$, the fourth explains $9.7 \%$, the fifth explained $7.5 \%$, and the sixth explained $6.7 \%$.

TABLE IIIII

WEIGHTS AND ASSOCIATED STATISTICS OF INDICATORS IN MEKONG RIVER DELTA

\begin{tabular}{|l|c|c|c|}
\hline \multicolumn{1}{|c|}{ Indicators } & Mean & Std.deviation & Weight: PC1 \\
\hline Rainfall change & 0.403 & 0.261 & -0.161 \\
\hline Temp. change & 0.385 & 0.316 & 0.255 \\
\hline Sea level change & 0.489 & 0.473 & 0.276 \\
\hline High rainfall ex & 0.457 & 0.280 & 0.250 \\
\hline Low rainfall ex & 0.474 & 0.292 & 0.251 \\
\hline High temp. ex & 0.501 & 0.273 & -0.144 \\
\hline Low temp. ex & 0.417 & 0.264 & -0.298 \\
\hline Elevation & 0.577 & 0.344 & 0.364 \\
\hline Paddy land & 0.512 & 0.326 & -0.334 \\
\hline Rural density & 0.449 & 0.323 & -0.200 \\
\hline Rain-fed rice & 0.133 & 0.272 & 0.347 \\
\hline Farm org. & 0.644 & 0.295 & 0.143 \\
\hline Literacy rate & 0.385 & 0.345 & -0.075 \\
\hline Rice output & 0.599 & 0.339 & 0.083 \\
\hline Share of rice income & 0.622 & 0.257 & 0.176 \\
\hline Agri. employees & 0.543 & 0.332 & -0.331 \\
\hline Poverty & 0.382 & 0.323 & 0.140 \\
\hline
\end{tabular}

Then, the first principal component was chosen to construct the climate change vulnerability index of Mekong River Delta. The weights of indicators on components 1 and their associated statistics are shown in Table 3. Among the exposure indicators, changes in temperature, sea level and high and low rainfall extremes have positive weights while change in rainfall and high and low temperature extremes have negative weights. Highest weights belonged to the indicators of sensitivity while indicators of adaptive capacity had lower weights compared to others.

The vulnerability index is calculated based on the formula of Filmer and Pritchett (2001) which use the indicator value, mean value and standard deviation of the indicators. The vulnerability level in Mekong River Delta ranged from -3.91 to 5.46. The result fits with PII estimation when areas that have coastal lines have higher vulnerability indexes. The two provinces that have high vulnerability indices were $\mathrm{Ca} \mathrm{Mau}$ and Tra Vinh which are located at the end of the Southern part of the country; these two provinces have low elevation ( 1 meter) and high rate of rain-fed rice; $\mathrm{Ca} \mathrm{Mau}$ is the province that has highest extremes in rainfall and temperature. Provinces that have medium vulnerabilities (ranging from 0 to 2) are Bac Lieu; Soc Trang and Ben Tre were the provinces that have low rice production and vulnerable to sea level rise. All of the six provinces that have medium low vulnerabilities (ranging from 0 to -2 ) are located further inland. An Giang and Dong Thap have lowest vulnerability; these two provinces have low dependence on agriculture, low poverty rate, low value of high and low rainfall extremes, do not have any rain-fed rice area, and are not subjective to projected sea level rise.

This estimation implies that from current prone state and under futurer projected conditions, the coastal provinces will continue to be heavily damaged, which will lead to a threat to rice production in these areas.

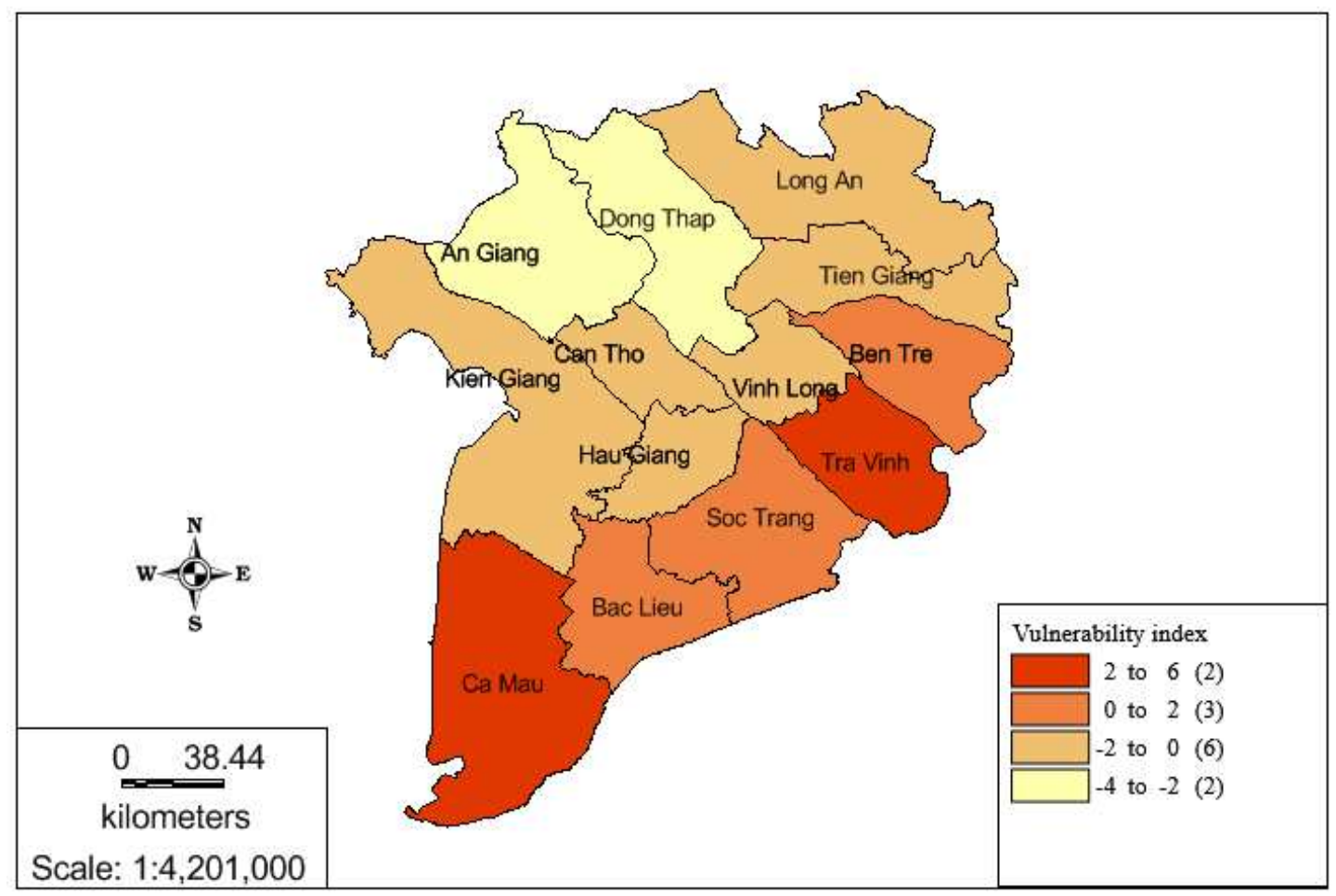

Fig. 5 Vulnerability map of rice farming provinces in Mekong River Delta 


\section{Projecting changes in rice paddy}

From the baseline in 1980 and projected climate in scenarios from MONRE [5], climate conditions in 2030 and 2050 were computed for the low, medium and high emission scenarios. The climate change scenarios for Vietnam was developed based on GHG emission scenarios developed by IPCC [28] which are: low emission scenario (B1); medium emission scenario (B2, A1B); and high emission scenario (A2, A1F).

The trends of rainfall in Mekong Delta River's climate scenarios are decreases from December to May (Winter and Spring) and increases from June to November (Summer and Autumn). The reductions of rainfall from December to February (Winter) is higher than from March to May (Spring) and the increases from June to August (Summer) is lower than from September to November (Autumn). The trends of temperature in climate scenarios are increases during all months, the trend from December to May (Winter and Spring) is lower than from June to November (Summer and Autumn).

There are possible 4 seasons of paddy in Mekong River Delta: Spring season which starts from November or December; Autumn season starts from April; Winter season starts from May or June; and Autumn-Winter season which starts from August.

Under the observed climate conditions and not taking into considering the affects from diseases, the estimated Spring season paddy productivity in 2011 in Mekong River Delta is 64.75 quintals per hectare, 52.64 quintals per hectare in Autumn season, 43.14 quintals per hectare in Winter season and 49.88 quintals per hectare in Autumn-winter season.Under the $\mathrm{CO}_{2}$ rainfall and temperature conditions in low emission scenarios, there would be reductions in paddy productivity in all seasons in 2030 and 2050 assuming that other factors are constant. The most reduction happened in Spring season with $9 \%$ reduction in 2030 and $6 \%$ reduction in 2050, the changes in Autumn and Autumn-winter season were nearly equal. Because there were only slight differences in temperature and rainfall between difference scenarios, changes in productivity between the three scenarios are similar.

The reductions in spring paddy which were greater than in the remaining three seasons may be attributed for the changes in rainfall amount. The paddy in spring season is planted from November and matures in February, but it has to suffer $6 \%$ reduction in rainfall from December to February ( $75 \%$ of season length) while other planting seasons receive less reduction in rainfall in terms of length ( 1 to 2 months) and magnitude (3\% reduction).

The impacts of changes in climatic conditions can be viewed through temperature and water stresses during the crop cycle. Because the temperature in Mekong River Delta is tropical, it is favorable for the development of paddy. Even though there were increases in both minimum and maximum temperature, there were still no temperature stresses on the crop cycle.

In Spring season, under the observed climate, there is water stress on stomatal closure (7\%). Under the 2030 climatic scenarios, due to the decreases of rainfall within months of Spring season, the water stresses on stomatal closure has increased to $14 \%$ in low and medium emission scenarios and $13 \%$ in high emission scenario. From 2030 to 2050 , there are decreases in water stresses to $9 \%$ low emission scenario and $10 \%$ in medium and high emission scenarios.

For Autumn paddy, because it starts in April which is still in the dry season, there is $6 \%$ of water stress on stomatal closure. However, in the three scenarios, rainfall amounts within this planting season would be increased which will reduce the water stress down to $4 \%$.

There was no water stress in Winter season and Autumnwinter season because these planting seasons happen in rainy season. Therefore, they receive great amount of water in both observed and projected climate conditions.

TABLE IV

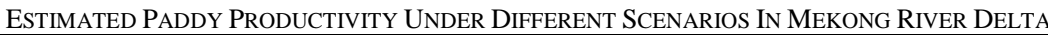

\begin{tabular}{|c|c|c|c|c|c|c|c|c|c|}
\hline \multirow{2}{*}{ Scenario } & \multirow{2}{*}{ Year } & \multicolumn{2}{|c|}{ Spring paddy } & \multicolumn{2}{|c|}{ Autumn paddy } & \multicolumn{2}{|c|}{ Winter paddy } & \multicolumn{2}{|c|}{ Autumn-winter } \\
\hline & & Productivity & Change & Productivity & Change & Productivity & Change & Productivity & Change \\
\hline & 2011 & 64.75 & & 52.64 & & 43.14 & & 49.88 & \\
\hline \multirow{2}{*}{ Low } & 2030 & 58.72 & $-9.31 \%$ & 51.45 & $-2.26 \%$ & 41.26 & $-4.36 \%$ & 47.71 & $-4.35 \%$ \\
\hline & 2050 & 60.16 & $-7.09 \%$ & 51.37 & $-2.41 \%$ & 41.26 & $-4.36 \%$ & 47.71 & $-4.35 \%$ \\
\hline \multirow{2}{*}{ Medium } & 2030 & 58.73 & $-9.30 \%$ & 51.45 & $-2.26 \%$ & 41.26 & $-4.36 \%$ & 47.71 & $-4.35 \%$ \\
\hline & 2050 & 60.66 & $-6.32 \%$ & 51.37 & $-2.41 \%$ & 41.26 & $-4.36 \%$ & 47.71 & $-4.35 \%$ \\
\hline \multirow{2}{*}{ High } & 2030 & 58.81 & $-9.17 \%$ & 51.45 & $-2.26 \%$ & 41.26 & $-4.36 \%$ & 47.71 & $-4.35 \%$ \\
\hline & 2050 & 60.66 & $-6.32 \%$ & 51.37 & $-2.41 \%$ & 41.26 & $-4.36 \%$ & 47.71 & $-4.35 \%$ \\
\hline
\end{tabular}

\section{CONCLUSIONS}

The results of potential impact index and climate change vulnerability index both showed that areas which are adjacent to the sea are more vulnerable to extreme events. The similar in the distribution of the magnitude of the two indexes implies that at the current prone state of coastal areas, if there is no appropriate adapting and mitigating strategy, increases in future extreme events will damage the rice production in the region. Under some assumptions to simplify the practical conditions, the results for the simulation model of paddy yield under different scenarios 
showed decreases in the paddy yield in Mekong River Delta. Specifically, the yield of Spring paddy decreased 6\%, Autumn paddy decreased $2 \%$, Winter paddy decreased $4 \%$ and Autumn-winter paddy decreased $4 \%$ in 2050.

The methodologies used in the study have both limitations and strengths. It is recommended for future researches to go into further study of details of the provinces and/or increase and improve the vulnerability indicators to be able to get a more accurate prone state to climate change. In the simulation model, the accuracy of the estimated productivity may be reduced because there are other factors that are assumed to be constant through years such as diseases occurance due to increasing temperature. Besides, the impacts of being flooded by sea level rise and salt water invasion were not inputted. However, the results are still valid as signals for potential consequences that may happen in the future.

\section{REFERENCES}

[1] General Statistics Office, "Statistical Yearbook of Vietnam 2011," Statistical Publishing House, 2011.

[2] N. H. Ninh, Flooding in Mekong River Delta, Vietnam, 2007.

[3] S. Noh et al., "Influence of salinity intrusion on the speciation and partitioning of mercury in the Mekong River Delta," Geochimica et Cosmochimica Acta, vol. 106, no. 0, pp. 379-390, 2013.

[4] W. N. Adger et al., "Adaptation to climate change in the developing world," Progress in Development Studies, vol. 3, pp. 179-195, 2003.

[5] MONRE, "Climate Change, Sea Level Rise Scenarios for Vietnam," Publisher of Environment - Resources and Vietnam Maps, 2012.

[6] P.-S. Yu, T.-C. Yang, and C.-C. Chou, "Effects of Climate Change on Evapotranspiration from Paddy Fields in Southern Taiwan," Climatic Change, vol. 54, no. 1-2, pp. 165-179, 2002/07/01, 2002.

[7] R. Wassmann et al., "Chapter 3 Regional Vulnerability of Climate Change Impacts on Asian Rice Production and Scope for Adaptation," Advances in Agronomy, L. S. Donald, ed., pp. 91-133: Academic Press, 2009.

[8] L. Tuan, and S. Chinvanno, "Climate Change in the Mekong River Delta and Key Concerns on Future Climate Threats," Environmental Change and Agricultural Sustainability in the Mekong Delta, Advances in Global Change Research M. A. Stewart and P. A. Coclanis, eds., pp. 207-217: Springer Netherlands, 2011.

[9] P. Chaudhry, and G. Ruysschaert, Climate change and human development in Viet Nam: A case study, 2007.

[10] K. Västilä et al., "Modelling climate change impacts on the flood pulse in the Lower Mekong floodplains," Water and Climate Change, vol. 1, no. 1, pp. 67-86, 2010.

[11] T. V. H. Le et al., "The combined impact on the flooding in Vietnam's Mekong River delta of local man-made structures, sea level rise, and dams upstream in the river catchment," Estuarine, Coastal and Shelf Science, vol. 71, no. 1-2, pp. 110-116, 2007.

[12] R. Wassmann et al., "Sea Level Rise Affecting the Vietnamese Mekong Delta: Water Elevation in the Flood Season and Implications for Rice Production," Climatic Change, vol. 66, no. 1-2, pp. 89-107, 2004/09/01, 2004

[13] B. Yu et al., Impacts of Climate Change on Agriculture and Policy Options for Adaptation: The Case of Vietnam, 2010.

[14] R. Padmaja, and R. Banerjee, "Quantitative assessment of Vulnerability to Climate Change (Computation of Vulnerability Indices)," in Training on Agro-climatic Analysis and Use of Qualitative Tools for Data Collection, 2009.

[15] IPCC, Climate Change 2001: Impacts, Adaptation and Vulnerability. Contribution of Working Group II to the Third Assessment Report of the Intergovernmental Panel on Climate Change, Cambridge University Press, Cambridge, 2001.

[16] D. J. Abson, A. J. Dougill, and L. C. Stringer, "Using Principal Component Analysis for information-rich socio-ecological vulnerability mapping in Southern Africa," Applied Geography, vol. 35, no. 1-2, pp. 515-524, 2012.

[17] A. $\mathrm{Li}$ et al., "Eco-environmental vulnerability evaluation in mountainous region using remote sensing and GIS-A case study in the upper reaches of Minjiang River, China," Ecological Modelling, vol. 192 , no. $1-2$, pp. $175-187,2006$.

[18] D. Sietz, M. K. B. Lüdeke, and C. Walther, "Categorisation of typical vulnerability patterns in global drylands," Global Environmental Change, vol. 21, no. 2, pp. 431-440, 2011.

[19] S. Hughes et al., "A framework to assess national level vulnerability from the perspective of food security: The case of coral reef fisheries," Environmental Science \& Policy, vol. 23, no. 0, pp. 95$108,2012$.

[20] D. P. Johnson et al., "Developing an applied extreme heat vulnerability index utilizing socioeconomic and environmental data," Applied Geography, vol. 35, no. 1-2, pp. 23-31, 2012.

[21] Y. M. Hoque et al., "Watershed reliability, resilience and vulnerability analysis under uncertainty using water quality data," Journal of Environmental Management, vol. 109, no. 0, pp. 101-112, 2012.

[22] Deon Filmer, and L. H. Pritchett, “ Estimating Wealth Effects Without Expenditure Data-Or Tears: An Application to Educational Enrollments in States of India," Demography vol. 38, no. 1, pp. 115 1322001.

[23] J. Koh, Assessing Local Vulnerability to Climate Change and its Implications: the Case of Gyeonggi-Do, Gyeonggi Research Institute, 2010.

[24] G. Nelson, Assessing the Vulnerability of Agriculture to Climate Change in Sub-Saharan Africa, International Food Policy Research Institute, 2010.

[25] Supin Wongbusarakum, and C. Loper, Indicators to assess community level social vulnerability to climate change: An addendum to SocMon and SEM- Pasifika regional socioeconomic monitoring guidelines, 2011.

[26] Glwadys Aymone Gbetibouo, and C. Ringler, "Mapping South African Farming Sector Vulnerability to Climate Change and Variability," International Food Policy Research Institute (IFPRI), 2009 , p. 52.

[27] W. N. Adger, "Social Vulnerability to Climate Change and Extremes in Coastal Vietnam," World Development, vol. 27, pp. 249-269, 1999.

[28] IPCC, Special Report on Emissions Scenarios, 92-9169-113-5, 2000. 